\title{
ENGINEERING GEOLOGICAL CHARACTERISATION OF BLOCK-IN-MATRIX ROCKS
}

\author{
Nikolaidis G. ${ }^{1}$ and Saroglou C. ${ }^{2}$ \\ ${ }^{I}$ Department of Civil and Environmental Engineering, Imperial College London, Skempton \\ Building, SW7 2AZ, London, United Kingdom, georgios.nikolaidis14@imperial.ac.uk \\ ${ }^{2}$ Dept of Geotechnics, School of Civil Engineering, National Technical University of Athens, 9 \\ Iroon Polytechniou str., 15780 Athens, Greece, saroglou@central.ntua.gr
}

\begin{abstract}
Block-in-matrix rocks ("bimrocks") are complex, mixed and heterogeneous formations of competent blocks embedded in weaker matrix. The inherent difficulty of sampling and consequently, laboratory testing of bimrocks leads to considerable challenging in geotechnical design and assessment of their engineering behaviour. An approach for the characterisation of "bimrocks" is the use of stereological analysis that extrapolates one-dimensional or two-dimensional data to estimate the block volumetric proportion. This has been an established approach of dealing with bimrocks and melanges for the last two decades. This paper presents the parameters that are considered important for the engineering characterisation of such complex formations, while a case study from a bimrock in NW Greece is discussed.

Keywords: Bimrock, Mélange, Red Flysch, Ophiolites.
\end{abstract}

\section{Пврі́ $\lambda \eta \psi \eta$}

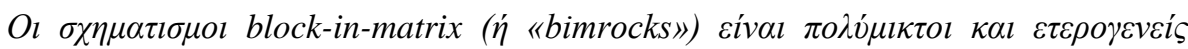

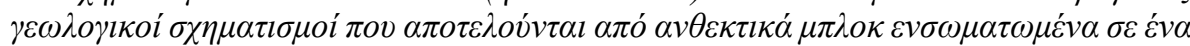

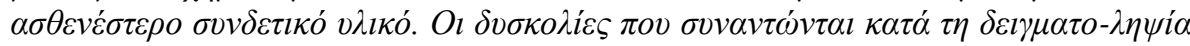

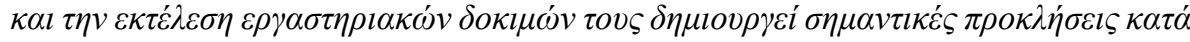

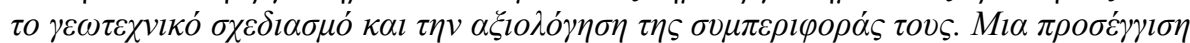

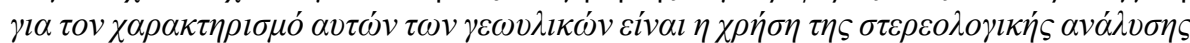

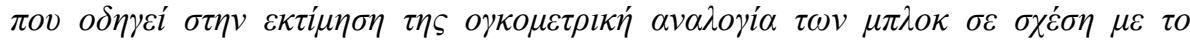

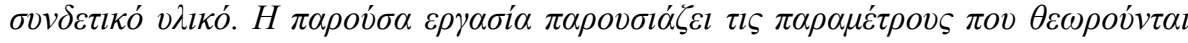

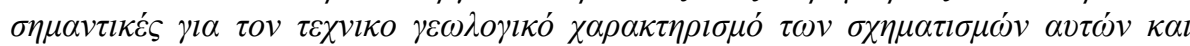

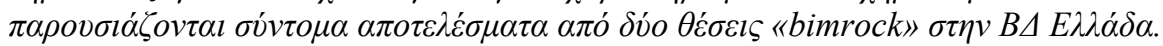

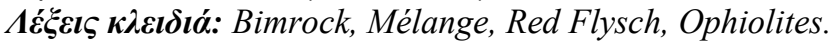

\section{Introduction}

The expression "block-in-matrix rocks" was introduced by Raymond (Raymond, 1984) and incorporates similar terminologies such as mega-breccias, olistostromes, argille scagliose, friction carpets, wildflysch, varicoloured clays and sedimentary chaos (Medley and Zekkos, 2011).

The term "bimrock" was proposed by Medley in his attempt to study the engineering properties of these geological mixtures and was defined as "a mixture of rocks, composed of geotechnical significant blocks within a bonded matrix of finer texture" (Medley, 1994). To satisfy the term "geotechnical significant" the blocks must satisfy three criteria (Medley, 1994): 
1. A mechanical difference in terms of strength exists between the matrix and the blocks.

2. There are significant ratios between the largest and the smallest blocks, and a characteristic engineering dimension of the rock mass. These dimensions have a wide range, referred as engineering range that depends on the scale of the engineering project in question.

3. The volumetric proportion of the block must vary between the values of $25 \%$ to $75 \%$.

Bimrocks are common in active or dormant orogenic belts such as the Alpine or the Franciscan complex. The challenge of these geologic materials is the problematic and chaotic nature prohibiting a simplistic approach for estimating their spatial distribution as well as their complexity and challenging sampling during ground investigations result in lack of good quality laboratory and insitu testing.

The aim of this paper is to propose a number of factors that can be straightforwardly assessed in the field so as to get an initial evaluation of the properties of the bimrocks studied. For this purpose a case study is presented.

\section{Bimrock Characterisation Parameters}

\subsection{Field Approach}

Ideally, a fieldwork associated with bimrocks should include an exploratory investigation with core sampling and laboratory testing techniques as a following stage. Due to the previously discussed difficulties in obtaining good quality samples and the fact that in most cases these are unrepresentative and of the actual complex ground conditions, those methods are costly and may yield erroneous results. Thus, studying outcrops at any possible exposure, such as beach or river cliffs and road cuttings is the standard way of practice as a first evaluation step.

Briefly, the suggested methodology to characterise bimrocks, which was followed in the present study, is the following: a) Desk Study and Field Reconnaissance, b) Walkover Survey and site(s) selection, c) Selection of appropriate project scale: "Characteristic engineering dimension", $\left.\left(\mathrm{L}_{\mathrm{C}}\right), \mathrm{d}\right)$ acquisition of Linear Scanlines for Linear Block Proportions of the studied outcrops, e) engineering geological description according to the a list of proposed parameters, f) image analysis for stereological analysis (Volumetric Block Proportion, Block Size Distribution) of the studied bimrocks, g) Classification and Characterisation of the block in matrix rocks.

\subsection{Parameters}

The main parameters that the characterisation of the bimrock outcrops is based are the following:

8. Linear Block Proportion

9. Bimrock Strength

10. Matrix Complexity

11. Block Classification

12. Bimrock Complexity

13. Orientation of Blocks

\subsection{Scale and Block Proportion}

Initially, a characteristic engineering dimension $L_{C}$ at scale of engineering interest; e.g.: height of cut-slope, tunnel diameter; diameter of laboratory specimen etc.

The method of measuring the block proportion and the use of scanlines has been thoroughly addressed by researchers such as Medley. The proposed guideline from this project is that during the one-dimensional measurement of block proportions, the greater the number of available scanlines the more accurate the results. An equal, or at least similar number of measurements from 
both the parallel/along the length of the exposure and perpendicular to the length of the exposure is suggested. Even if the use of image analysis for a two-dimensional or 3D block proportion is used at a latter stage, an initial assessment using the "old-fashioned" way of a tape measure is always beneficial for an early assessment.

\subsection{Strength of the Blocks and the Matrix}

The block/matrix strength ratio should be checked in order to define that the material in question has a sufficient mechanical difference in terms of strength between the matrix and the blocks. The following criteria can be used (Medley and Zekos, 2010):

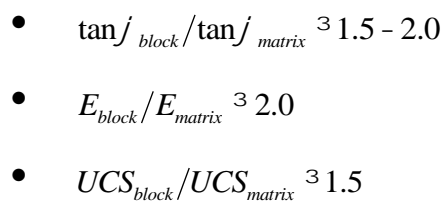

The bimrock strength is assessed via Schmidt hammer testing, gaining values for the Unconfined Compressive Strength (UCS) of the blocks and matrix. Alternatively, the Point Load testing can be used. The strength properties of the matrix and the blocks can be evaluated reasonably using the ISRM (1981) classification of rock and soil, using field identification and assigning an approximate range of the uniaxial compressive strength (MPa). This takes place in the case of low UCS values (weak rock, soil types), where Schmidt Hammer test results are inaccurate. Thus, the strength of the matrix should be estimated using the ISRM chart (Table 1).

For large blocks, the Schmidt hammer measures the properties of the intact rock, however for fragmented blocks the measurement mainly indicates the rock mass quality rather than the intact rock. Therefore the fragmentation of the bimrock blocks is of great importance. Readings from geometrical disproportions of blocks or deteriorated block surfaces should be taken into consideration, due to the fact that mélanges are supposed to be weakened throughout their mass and the representation only of fresh intact rock blocks is irrelevant in this case. The orientation of readings is not supposed to be of relevance in bimrocks, as the orientation of the blocks will change throughout their spatial distribution.

Different types of Schmidt hammers exist, mainly the L and N-type. The field measurements were conducted with an L-type hammer of a rebound number scale of 100. Hammers of a rebound number scale less than 100 can be used, but high strength blocks will not be correctly estimated. The conversion charts and calibration curves used had a maximum UCS value of $400 \mathrm{MN} / \mathrm{m}^{2}$ for the Schmidt hammer and $350 \mathrm{MN} / \mathrm{m}^{2}$ for the point load test. Blocks with values higher than $100 \mathrm{MN} / \mathrm{m}^{3}$ will be assumed with a maximum value of $100 \mathrm{MN} / \mathrm{m}^{2}$, due to the fact that if such strong rocks (e.g. fresh basalt) are part of the bimrock, high stresses will lead to matrix failure long before reaching values of $100-400 \mathrm{MN} / \mathrm{m}^{2}$ and the induced stresses will surpass the strength of the intact rock or the rockmass forming the block, a bimrock-based analysis of the material is then unnecessary.

After the strength values of the blocks have been measured, an assessment of the relative percentages of the different block lithologies is necessary. Variable block strengths will contribute differently to the overall bimrock strength.

For the assessment of the proportion of the different lithologies of the blocks, the construction of a conceptual grid during the observation of the outcrop is proposed. The square root of the area $(\sqrt{ } \mathrm{A})$ containing the measured blocks with the characteristic engineering dimension - $\mathrm{L}_{\mathrm{C}}$ (Medley, 2002) should be used. At a latter step, the use of image analysis software in order to distinguish the proportion of blocks of different lithology is proposed. The blocks are assigned a relative percentage regarding their derived proportions that make up the total block mass of the bimrock. Their percentages are then multiplied with the strength index values measured previously to give the overall block strength index value. 
The composition of the matrix governs much of the strength properties of the bimrock (tortuous failures forming in the matrix). One essential preliminary identification in the field is the nature of the matrix, i.e. rock type or soil type. This is particularly challenging for weak rocks and weathered exposures. The threshold value is defined as the "Stiff soil" (0.6 MPa) from the ISRM classification (1981) and it can be assessed using the strength recognition ISRM chart. But, due to the difficulties in getting an accurate value for low strength matrices using a Schmidt Hammer, only "Weak Rock" and above can be tested for their strength using Schmidt Hammer.

For soil matrix, the threshold value proposed is $0.6 \mathrm{MN} / \mathrm{m}^{2}$. For Soil Type matrices, sampling for Particle Distribution Curves is recommended. It is evident, that laboratory testing (triaxial, shear box, etc.) is the optimum solution, but as this classification is aimed as an initial tool of assessing bimrocks in the field. For Weak Rocks $\left(0.6\right.$ to $\left.12.5 \mathrm{MN} / \mathrm{m}^{2}\right)$, Schmidt hammer could prove also inaccurate. Based on the description and properties the engineering geologist/geotechnical engineer will decide the value of the matrix composition.

The measured Schmidt hammer test rebound number values are then converted to UCS values. The values will range from a few kilo Pascals up to several mega Pascals. An upper limit is proposed, of $100 \mathrm{MPa}$ or $100 \mathrm{MN} / \mathrm{m}^{2}$.

\subsection{Cumulative Bimrock Strength}

In order to determine the strength of the bimrock, a parameter termed "Cumulative Bimrock Strength" is proposed which is a straightforward estimation method of the bimrock's UCS value. Although simplistic, it is considered as an initial appreciation of the strength of the bimrock, as defined only by the UCS of the Matrix and the UCS of the blocks.

The linear block proportion measured is multiplied with the $\mathrm{UCS}_{\text {block }}$ and the matrix proportion

multiplied with the defined $\mathrm{UCS}_{\text {matrix }}$

. The results will have

a maximum possible value of $100 \mathrm{MPa}$.

\section{Equation 2 - Cumulative Bimrock Strength (CBS)}

$\mathrm{C} B S=\frac{\text { Block Proportion (\%) }}{100} * \mathrm{UCS}_{\text {Block }} \div+\frac{\text { Matrix Proportion }(\%)}{100} * \mathrm{UCS}_{\text {Matrix }} \div$

\subsection{Bimrock Strength}

"Bimrock strength" parameter is one of the most fundamental quantities of the proposed characterisation. For the calculations of the Bimrock Strength parameter, all the previous steps analysed are necessary. The maximum possible value is 100 . The "Bimrock Strength" is defined by the following equation: 
Equation 3 - Bimrock Strength (BS)

$\mathrm{BS}=\frac{\text { Cumulative Bimrock Strength }}{200-\left(\mathrm{UCS}_{\text {Block }}+\mathrm{UCS}_{\text {Marrix }}\right)} 100$

\subsection{Matrix Complexity}

The complexity of the matrix is relevant to the isotropy of the fabric. It is quantitate of the how complex the matrix is three-dimension. There are three proposed complexity structures: a) Nonsheared, b) Sheared and foliated, c) Confining Schistosity.

Each category reflects the influence of matrix geometry to strength. "Non-sheared" is considered as the weakest condition and "Confining Schistosity" as the optimal condition, due to the fact that in these deformed and chaotic structures the matrix seems to "flow" around the blocks contributing further to their confinement. This flow is the local wrapping of the foliation around blocks with consistent or alternating orientations. The foliation orientations should be described, sketched and mapped at an outcrop scale when possible, since they have an impact upon the anisotropy in the strength of the melange.

Table 1 - Rock Strength approximation in the field (Waltham, 2009).

\begin{tabular}{|c|c|c|c|}
\hline \multicolumn{4}{|c|}{ Strength Recognition and Description } \\
\hline & Rock/Soil description & $U C S(M P a)$ & Field Properties \\
\hline \multirow{7}{*}{ 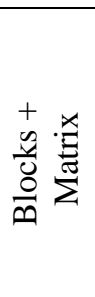 } & Very strong rock & $>100$ & Firm hammering to break \\
\hline & Strong rock & $50-100$ & Break by hammer in hand \\
\hline & Moderately strong rock & $12.5-50$ & Dent with hammer pick \\
\hline & Moderately weak rock & $5.0-12.5$ & Cannot cut by hand \\
\hline & Weak rock & $1.5-5.0$ & Crumbles under pick blows \\
\hline & Very weak rock & $0.6-1.5$ & Break by hand \\
\hline & Very Stiff Soil & $0.3-0.6$ & Indent by fingernail \\
\hline \multirow{4}{*}{ 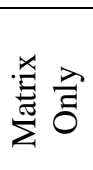 } & Stiff Soil & $0.15-0.3$ & Cannot mould in fingers \\
\hline & Firm Soil & $0.08-0.15$ & Mould by fingers \\
\hline & Soft Soil & $0.04-0.08$ & Mould easily in fingers \\
\hline & Very soft soil & $<0.04$ & Exudes between fingers \\
\hline
\end{tabular}

\subsection{Block classification parameters}

Block classification is based on the following factors: a) Fragmentation of blocks, b) Block size distribution, c) Shape of blocks. Melanges are usually associated with a significant stress history and the blocks should be expected to have a degree of fracturing. With complex formation such as bimrocks, block-poor and block-rich zones within the rock mass, which may vary significantly from the overall average.

The main issue lies with the extrapolation of the "blockiness" level from a number of observed blocks, to the whole mass of the bimrock, expecting the same behavior. The lithology of the block can be considered more typical of what to expect for the whole bimrock mass from outcrop scale, compared to the fracture pattern of the blocks. Also the quality of the discontinuities will considerably vary. Furthermore the hydrogeological properties of mélanges are complex and weathered joint surfaces can be expected at depth, rather than solely at surface conditions. It in noted that blocks that are intensely fractured may exhibit little strength contrast with matrix and should then be characterised as matrix (Medley and Sanz, 2004).

The assessment of the block fragmentation can be easily portrayed by the "Structure" parameter of the Geological Strength Index (Marinos, Marinos and Hoek, 2005), with the best case being the "INTACT" blocks and the poorest block structure the "DISINTERGATED" value. Bimrocks are highly complex 
materials thus any discontinuity assessment could prove erroneous as they don't share the persistence of typical rockmasses and could be a local feature or the result of surface conditions.

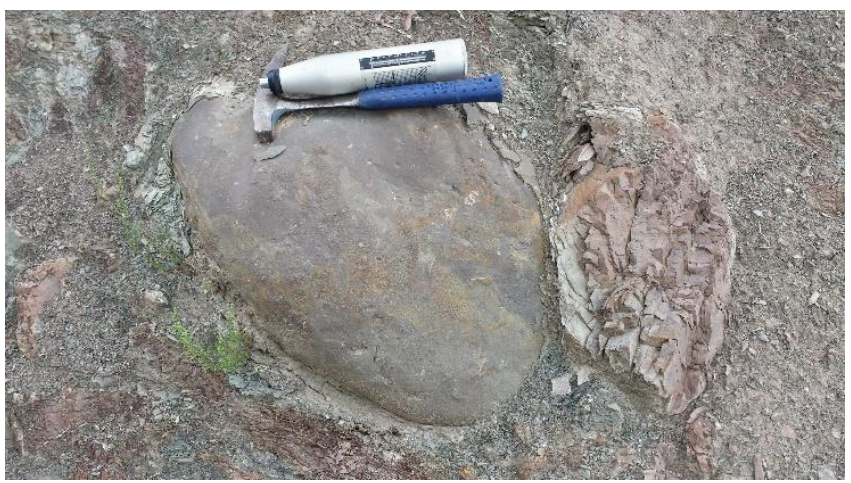

Figure 1 - Massive sandstone block in contact with highly fractured siltstone block.

A concern, as is portrayed by Figure 1 is that different rock compositions have to be assigned a single value. The sandstone block is much more component and it appears intact. On the other hand, the siltstone block is highly fractured. If both values were used in the way that the "Block Strength" parameter would overpredict the geomechanical properties of the blocks, since massive sandstone blocks were scarce. The authors suggest that for the "Fragmentation" factor only the block lithology that has the highest percentage should taken under consideration. If two or more block lithologies are of roughly equal quantities, the weakest material should only be considered.

The block size distribution of a bimrock is an important strength parameter. The more uniformly sized is a bimrock the planar and less undulating the failure plane will be. A bimrock with low block size distribution will have lower shear resistance strength values (Medley and Zekkos, 2010), increasing mainly the angle of internal friction $(\varphi$ '). Thus, the more "well graded" the bimrock, the more tortuous the shear planes. For an accurate block size distribution analysis the method used by Medley (1994) is considered essential.

The shape of the blocks is analysed by measuring the long and short axis of individual blocks in an unsystematic pattern across the outcrops. These blocks can then be converted into a ratio than enables the determination of any preferred orientation and shape of the blocks. However, the process of measuring block axis for each outcrop can be time consuming with in cases, dubious results. An example is Location 4, the largest observed block had totally different orientation compared to the surrounding blocks and its almost perfect tabular shape was in total contrast with the smaller, rounded, and slightly elongated majority of blocks. Thus, a simple classification based on shape and elongation is proposed, using a sphericity chart, with more rounded and spherical (axis ratio $~ 1$ ) blocks having the lowest values and elongated, angular blocks the highest.

\subsection{Orientation of Blocks}

The "Orientation of Blocks" parameter is defined as the relative orientation of the bimrock's block in relation with the engineering project, resulting in "favourable" or less favourable conditions. For example, for a cut slope the orientation is defined with relation with the slope face. For vertical foundation excavations the four (or more) vertical cuttings could define more than one different orientation, as the orientations of the blocks in relation with the different cuttings change. For tunnelling the block orientation could act as favourable or unfavourable conditions similar to bedding or foliation. Four classes are proposed (Figure 2):

- Bimrock is "Chaotic" (with no apparent Structure) - most favourable condition

- Bimrock shows a relative orientation between $0^{\circ}-30^{\circ}$. 
- Bimrock shows a relative orientation between $30^{\circ}-60^{\circ}$

- Bimrock shows a relative orientation between $60^{\circ}-90^{\circ}$ - least favourable condition

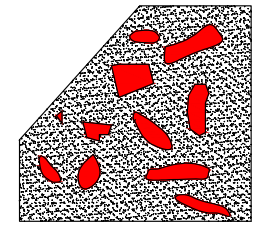

Chaotic

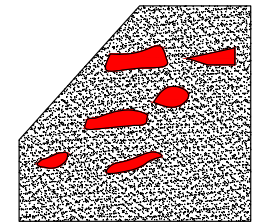

$0^{\circ}-30^{\circ}$

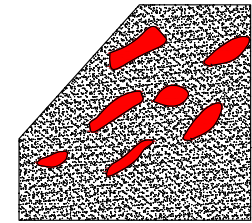

$30^{\circ}-60^{\circ}$

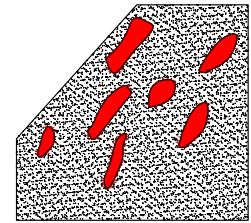

$60^{\circ}-90^{\circ}$

Figure 2 - The four proposed classes for the orientation of blocks.

\subsection{Degree of Complexity}

The overall complexity or "chaosity" of the bimrock is an attribute that deals with the apparent complexity of the bimrock, both matrix and blocks. It is a property assessed by the engineer and required accurate judgment during visual evaluation of the outcrop. Two parameters are recommended, the "degree of complexity" for chaotic melanges with no apparent structure, and the "sub-zoning of blocks" for bimrocks that show an apparent favorable direction of blocks.

\section{Analysis of bimrocks in case study areas}

\subsection{Site Geology}

All bimrock site locations examined are part of the Pindos Geotectonic zone (Figure 3). The Pindos Fold-and-Thrust belt comprises by a pre-orogenic Mesozoic, mainly carbonate sequence forming the eastern passive margin of the Apulian continent (Robertson et al., 1991), and a syn-orogenic Palaeocene to Eocene clastic sediment sequence (Richter, 1976).

The nappe complex forms an allocthonous tectonic stack of several kilometres and is bound by lowangle thrust faults, typical in this thin-skinned foreland area of a collision zone. Pindos zone is probably bounded by a sole or floor thrust at a depth of several kilometres (underlain by a metamorphic amphibolitic sole), with stacked nappes, as the roof thrust of one nappe serves as the floor thrust for the one above. The main geologic formations encountered are marine turbidites, commonly mentioned as "Flysch" in Greek literature and other marine deposits such as limestones.

The "bimrock-bearing" part of the Pindos Flysch is the "Red flysch", which is the basal unit of a three-section turbidite sequence. The top is described as a wildflysch unit displaying large and irregularly sorted blocks resulting from subaquatic sliding, underlain by a thick sequence of greywacke intercalations in the central part (Jacobshagen, 1986). The bottom Red flysch has a composition ranging between grey to red marls and reddish siltstones (Riedmüller et al., 2002; Marinos and Hoek, 2001). Thick competent layers of sandstone with siltstone interlayers alternate within the Red flysch sequence. This thinly to medium bedded sequence with interlayers of sandstone and siltstone is intensely folded and sheared at places. Disharmonic chevron and kink folding takes place which diminishes near faults (Riedmüller et al., 2002).

The tunnel constructions of Egnatia highway, especially the "Anilio" tunnel, encountered on many occasions "Red Flysch" bimrocks, with adverse conditions during tunnelling and failure of slopes at portals. The complex and challenging geology of the tunnel alignment resulted in a detailed structural geological analysis by means of outcrop studies and mapping in scale 1: 5000 (Riedmüller et al., 2002). The area is well known also for the slope instabilities, due to the presence of shear zones that form these tectonic melanges, or in general, poor quality rockmasses of flysch. At the Pindos zone, and especially at the south and southeast of Metsovon, a large area of ophiolitic rocks outcrops. Mylonitisation characterizes the western part of Pindos, where the ophiolites are much 
more tectonised in comparison with other areas. A later SW back-thrust placed the ophiolitic complex ultimately over the late Cretaceous-mid-Eocene Pindos flysch (Goricki et al., 2006). The mélange rocks exhibit the most incompetent lithological nature and present continuing deformation through its geological history. From Malakasi and Korydallos villages, up to further South East to the Koziakas Mountain, this oceanic crust complex comprised of ultramafic to mafic rocks (peridotites, dunites, spilites, etc.). Outcrops of exotic limestone blocks, referred to as "olistostrome" are evident throughout the Egnatia road from Malakasi B tunnel eastern portal, all the way to Korydallos and Panagia villages revealing Upper Cretaceous limestones, red Paleocene pelites and Eocene conglomerates along with the ophiolites (Papanikolaou, 2009).

The main formations of the studied area are shown in Figure 3:

1. Ophiolites of great heterogeneity with a varying their degree of weathering and highly sheared locally due to shear zones (Marinos and Hoek, 2001).

2. Limestone olistostrome blocks inside the ultramafic complex.

3. "Red Flysch" of Pindos.

4. Shear zones of the Red Flysch - Tectonic mélanges.

The results from 4 locations with bimrock outcrops are presented: a) two outcrop areas of Red Flysch melange and b) two of the ophiolitic melange:

- Location 2 and 4 (Red Flysch)

- Location 10 and 11 (Ophiolites)

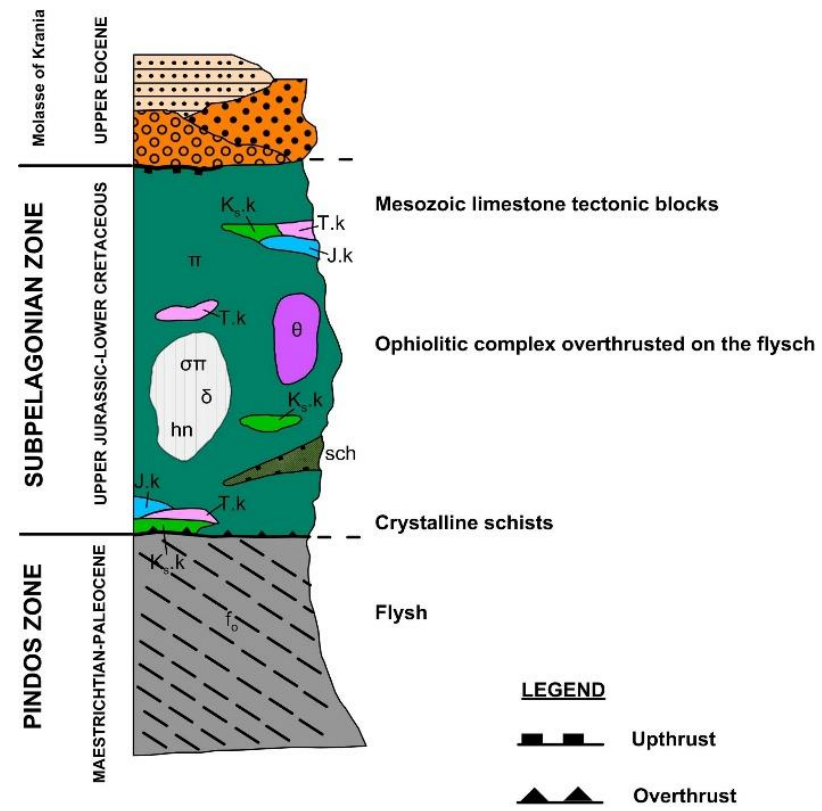

Figure 3 - Stratigraphic column of the Pindos Flysch and the overthrusting ophiolites (from I.G.M.E, 1980, modified). T.k: Triassic Limestones, J.k: Jurassic Limestones, Ks.k: Upper Cretaceous limestones, $\pi$ : peridotes, $\sigma \pi$ : spilite, $\delta$ : diabase, hn: red shales and radiolarites, $\theta$ : gabbro, sch: schists, fo: Flysch. 


\subsection{Image analysis}

An image analysis was performed for the bimrock outcrop in Location 4. The image presented in Figure was processed with ImageJ software. For an $\mathrm{L}_{\mathrm{C}}=1 \mathrm{~m}$ thus for a threshold value between blocks and matrix of $5 \mathrm{~cm}\left(0.05 \mathrm{~L}_{\mathrm{C}}\right)$, the aerial block proportion was calculated equal to $39.8 \%$.

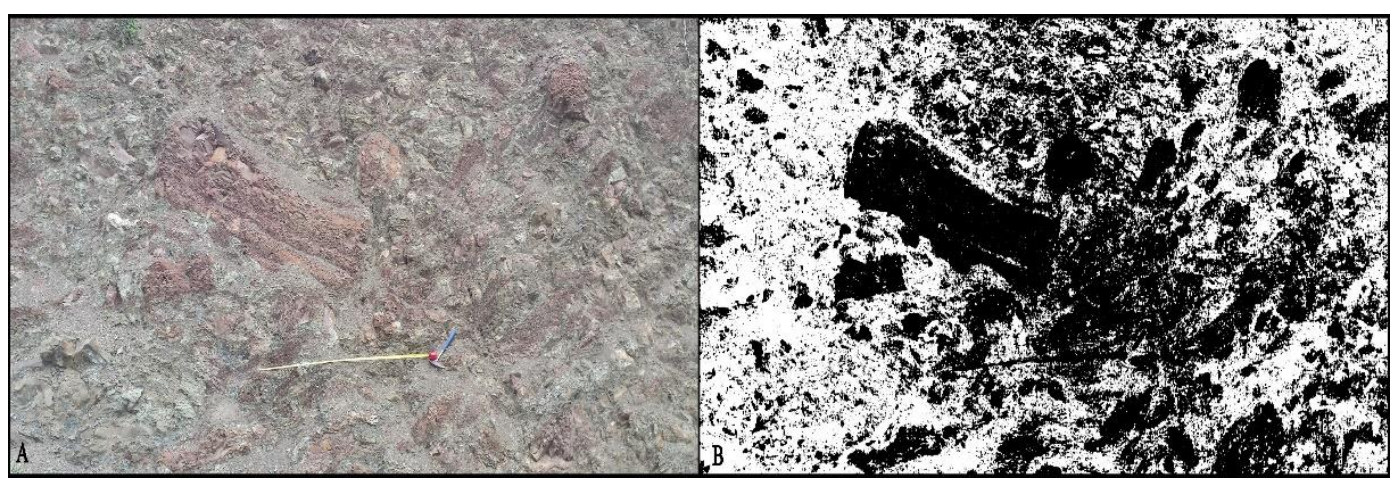

Figure 4 - a) Outcrop of red flysch b) processed image (Measuring tape dimensions: $1.5 \mathrm{~m}$ ).

\subsection{Bimrock characterisation}

The characteristic engineering dimension for the present study was selected equal to $1 \mathrm{~m}$.

The field reconnaissance showed that indeed the studied outcrops are characterised as "bimrocks". Both the block proportions ranged between 25\%-75\% and the mechanical difference between the blocks and the matrix was significant, with a strength ratio (block/matrix) ranging from 2.8 to 8.5.

Factors such as the Linear Block Proportion exhibited significant scatter when the scanlines intersected large blocks. This demonstrates the importance of acquiring a substantial number of linear scanlines, and preferably, photographs for image analysis (Areal Block Proportion). Comparing aerial block proportion determined from the image analysis with the field measurements of $(L B P)$, it is evident that the image analysis provides a more precise appreciation of the actual block proportion of the bimrocks.

Table 2 - Properties of studied bimrock melanges.

\begin{tabular}{|c|c|c|c|c|}
\hline & Location & $\mathrm{UCS}_{\text {block }}(\mathrm{MPa})$ & $\begin{array}{l}U_{\text {CS }} \text { Matrix } \\
\mathrm{UCS}_{\text {matrix }}(\mathrm{MPa})\end{array}$ & $\operatorname{LBP}(\%)$ \\
\hline \multirow{10}{*}{ 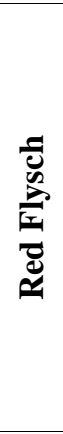 } & \multirow{4}{*}{2} & \multirow{4}{*}{$\begin{array}{l}\text { Siltstone: } 20 \\
\text { Sandstone: } 32 \\
\text { Average: } 21.8\end{array}$} & \multirow[t]{4}{*}{ 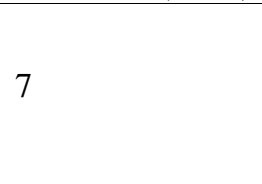 } & 43.2 \\
\hline & & & & 45.38 \\
\hline & & & & 52.4 \\
\hline & & & & Average: 47 \\
\hline & \multirow{6}{*}{4} & \multirow{6}{*}{$\begin{array}{l}\text { Siltstone: } 20 \\
\text { Sandstone: } 32 \\
\text { Average: } 22.4\end{array}$} & \multirow{6}{*}{8} & 50.4 \\
\hline & & & & $40.4(\mathrm{x} 2)$ \\
\hline & & & & 38.4 \\
\hline & & & & 31.3 \\
\hline & & & & 20.4 \\
\hline & & & & Average: 36.9 \\
\hline \multirow{6}{*}{ 苞 } & \multirow{3}{*}{10} & \multirow{3}{*}{34} & \multirow{3}{*}{4} & 58.94 \\
\hline & & & & 43.2 \\
\hline & & & & Average: 51.1 \\
\hline & \multirow{3}{*}{11} & \multirow{3}{*}{38} & \multirow{3}{*}{9} & 62.1 \\
\hline & & & & 48 \\
\hline & & & & Average: 50 \\
\hline
\end{tabular}


The aerial block proportion of the Red Flysch bimrocks changed drastically with increasing $\mathrm{L}_{\mathrm{C}}$ values, especially for those greater than $5 \mathrm{~m}$, as blocks larger than 1.5-2 were scarce in the shear zones of the Red Flysch. This was anticipated, as these bimorcks didn't exhibit scale independency.

\section{Discussion}

Block in matrix rocks are complex natural systems and concepts such as scale dependence should not be used without any further consideration. Even though melanges such as the Franciscan exhibit scale independence (Medley, 1994), no such statement can be claimed for the Pindos melanges. The ophiolitic complex containing limestone olistostromes is a potential candidate, but further investigation is needed.

The adopted Characteristic Engineering Dimension $\left(\mathrm{L}_{\mathrm{C}}\right)$ value has a profound effect on the bimrock analysis. When measuring the LBP, all blocks falling under the $0.05 \mathrm{~L}_{\mathrm{C}}$ value are classified as matrix. Accordingly, during image analysis, these blocks are treated the same. Even if these minor blocks are considered as matrix, their impact upon the strength of the bimrock can be substantial and has not been thoroughly studied.

Parameters such as the Matrix Complexity are subjective by nature. Thus, some experience is necessary and also their relative importance compared to other parameters such as the strength of the blocks/matrix should be smaller.

Although melanges are often encountered throughout the globe there is still a lack of understanding of their implication upon the engineering design and construction. Due to the nature of bimrocks, an appropriate characterisation of the materials requires a significant appreciation of geology. As melanges lack stratigraphic continuity, a simplistic approach of treating bimrocks as stratified materials is highly erroneous. Thus, qualified professionals such as engineering geologists, or experienced geotechnical engineers with substantial geologic background should be tasked with dealing with such geologic materials.

\section{References}

Goricki, A., Rachaniotis, N., Hoek, E., Marinos, P., Tsotsos, S. and Schubert, W., 2006. Support decision criteria for tunnels in fault zones, Proceedings of the 55th Geomechanics Colloquium, Salsberg.

Jacobshagen, V., 1986. Geologie von Griechenland. Berlin, Gebr. Borntraeger.

Marinos, P. and Hoek, E., 2001. The apporpriate use of geological information in the design and construction of the Egnatia Motorway tunnels. In: Marinos, P. and Marinos, P., eds., Egnatia Motorway Tunnels, 7/12/2001, 8/12/2001, Ioannina.

Marinos, V., Marinos, P. and Hoek, E., 2005. The geological strength index: applications and limitations, Bulletin of Engineering Geology and the Environment, 64(1), 55-65.

Medley, E. and Sanz Rehermann, P., 2004. Characterization of bimrocks (rock/soil mixtures) with application to slope stability problems, Proceedings: Eurock 2004 \& 53rd Geomechanics Colloquium Salzburg.

Medley, E. and Goodman, R.E., 1994. Estimating the block volumetric proportions of melanges and similar block-in-matrix rocks (bimrocks), Proceedings of the 1st North American Rock Mechanics Symposium. Jun 1 - 3 1994, Austin, TX, United states, A.A. Balkema, 851-851.

Medley, E.W., 2002. Estimating Block Size Distributions of Melanges and Similar Block-in-Matrix Rocks. In: Hammah, R., Bawden, W., Curran, J. and Telesnicki, M., eds., 5th North American Rock Mechanics Symposium (NARMS), July, Toronto, Canada, University of Toronto Press, 509-606.

Medley, E.W., 1994. The Engineering Characterization of Melanges and Similar Block-in-Matrix Rocks (Bimrocks), PhD. University of California at Berkely. 
Medley, E.W. and Zekkos, D., 2011. Geopractitioner approaches to working with antisocial mélanges, Geological Society of America Special Papers, 480, 261-277.

Papanikolaou, D., 2009. Timing of tectonic emplacement of the ophiolites and terrane paleogeography in the Hellenides, Lithos, 108(1), 262-280.

Raymond, L., 1984. Classification of melanges, Geological Society of America Special Papers, 198, 7-20.

Richter, D., 1976. Das Flysch-Stadium der Helleniden - Ein Überblick, Zeitschrift Der Deutschen Geologischen Gesellschaft Band, 127, 467-483.

Riedmüller, G., Schubert, W., Steidl, A. and Holzleitner, W., 2002. Prediction of Support for the Preliminary Design of the Anilio Tunnel (Egnatia Motorway), Felsbau, 20(4).

Robertson, A.H.F., Clift, P.D., Degnan, P.J. and Jones, G., 1991. Palaeogeographic and palaeotectonic evolution of the Eastern Mediterranean Neotethys, Palaeogeography, Palaeoclimatology, Palaeoecology. 87(1), 289-343.

Waltham, T., 2009. Foundations of Engineering Geology, 3rd edition. London; New York, Taylor $\&$ Francis, Spon Press. 